\title{
The Impact of Tourism Development on the Local Communities in Namibia
}

\author{
${ }^{1}$ Asa Romeo Asa, ${ }^{2}$ Bianca Tjizumaue, ${ }^{3}$ Harold Campbell, ${ }^{4}$ Johanna Pangeiko Nautwima \\ ${ }_{1,2,3,4}$ Namibia University of Science and Technology \\ Faculty of Management Sciences \\ Windhoek, Namibia
}

\begin{abstract}
This article aims to identify and explain the current challenges being faced due to the impact of tourism development on the local communities in Namibia. The Foreign-exchange earnings and balance of payment benefits derived from tourism receipts are considered a double-edged sword, meaning tourism can have both negative and positive impacts on the local communities. The money spent by tourists in the Namibian economy is significant towards local communities' development. This desk research found an appalling concern for many developing countries to over-depend on tourism to pursue economic growth and development. It is argued that this serves as a demonstration of how tourism development elevates the prices related to real estate and general costs of goods and services, which eventually leads to inflation. Finally, we assume that self-efficacy positively influences the involvement of local communities in tourism development which has positive implications on their quality of life regarding social and economic bearings. Additionally, local communities should be more supportive and instead have a positive attitude towards tourism development, thus resulting in a more profitable tourism sector. In concluding, the authors viewed that the government should also ensure that the local people are well informed about the importance of tourism, how it impacts economic development and the realization of a sustainable tourism strategy for Namibia.
\end{abstract}

Keywords: Community development; internal tourism; tourism development; pro-poor tourism; moderating effect; Namibia; self-efficacy; socio-cultural.

\section{Introduction}

In recent years, Namibia has attracted many tourists for numerous reasons, including safety, political stability, desert scenery, wildlife, cultural diversity, et cetera. This view is echoed in the 5th National Development Plan, "... Namibia is a remarkable and competitive destination because of its comparative advantages which include wide-open spaces with spectacular landscapes; abundant wildlife resources; diversity of experiences; excellent infrastructure; security, peace, and stability; and low population densities" (NPC, 2017). The State touts Tourism's socio-cultural benefits through its respective line ministries as highly significant towards the development and economic growth, as articulated in the current National Development Plan (NDP5). "... The tourism industry is an important contributor to the generation of foreign exchange earnings, investments, revenue, employment, rural development, poverty reduction, and the growth of the country's economy. Tourism also creates substantial direct and peripheral benefits because of its multiplier effect, based on its reliance on widespread supplies and services" (NPC, 2017).

This paper reports that Namibia has a growing global reputation as a premier destination for ecotourism. The foreign arrivals rate of tourist has grown with a record of 2.2 per cent in 2017, but was dampened by the Covid-19. Over the years, the toursim sector in Namibia has contributed significantly to the growth of small firms (Asa and Prasad, 2014). The infusion of foreign money into the local communities carries either direct or indirect benefits, it is argued in this article. The income from tourism has a multiplier effect in financing many productive projects, such as reinvestment into Namibian marketing attractions in overseas markets; provision of a source of income for many local transport shuttles; and salaries and wages of the local employees, who render services in the companies which host tourists.

International Journal of Operations Management, vol. 2, issue 2, pp. 7-16, January 2022 
Tourism can negatively impact the local community, but it can be minimized and measured against the positive effects of tourism. The positive impacts are much more than the negative impacts and are usually not considered critical compared to the benefits tourism offers. Nevertheless, it is an appalling concern for many developing countries to overdepend on tourism to pursue economic growth and development. This demonstrates how tourism development elevates the prices related to real estate and general costs of goods and services, which eventually leads to inflation.

As a result, we recommend adopting the Conceptual model for tourism development (cf. Figure 1 Conceptual model for tourism development). Here, the moderating effect of self-efficacy is seen as the endogenous effect of the belief among local communities to develop an attractive tourism sector based upon their knowledge, skillfulness, and competency, which stimulates them to devote their energy to creating their environment streamlined to attract more international and domestic tourists. The articulated view is that self-efficacy positively influences the involvement of local communities in tourism development which has positive implications on their quality of life regarding social and economic bearings. In addition, local communities should be more supportive and instead have a positive attitude towards tourism development, thus resulting in a more profitable tourism sector. It is further recommended that the Namibian government ensure that the local people are well informed about the importance of tourism and its impact on economic development.

\section{Literature Review}

This paper is based on desk research of the impact of tourism development on the local communities in Namibia. First, the focus of the literature review is informed by the expected economic benefits that tourism has on local communities (Walpole, 2000), in terms of increased employment opportunities, direct foreign-exchange earnings and balance of payment (Bojanic and Lo, 2016; Archer, 1995; Durbarry, 2002; Tribe and Liburd, 2016). Secondly, empirical studies published between 1992 and January 2019 were critically analyzed to generate a practical research framework (Figure 1 and Figure 3) that embraces the following issues: economic costs as effectors of over-dependence on tourism, inflation, and property values, and opportunity costs. The proposed framework, which is intended to help guide future empirical research in this field, suggests associations between tourism initiatives, self-efficacy, and the economic, socio-cultural, and moderating effects of the social impact of tourism on local communities (Belk, 1992; Lunenburg, 2011; Firouzmakan, 2015; Rampullo and Licciardello, 2015; Khandare, 2018; Zaei, 2013; Scholtz, 2014).

\section{Local Economic Benefits}

The central claims of tourism about economic growth and development in Namibia and elsewhere pertains to the prestige and respect the tourism sector has among the communities, businesses, and public office bearers. It is a promising claim of the potential impact of tourism on local economies that often leads to the formulation of favorable public policies aligned to nurturing the tourism sector. Tourism is an activity that affects the entire host local community in one way or another (Walpole, 2000). However, this paper section focuses mainly on tourism's economic benefits to local communities.

Evidence from the literature (Franke et al., 2015) showed a direct linkage between tourism activities and Gross Domestic Product (GDP), which means an increase in tourism activities leads to a rise in GDP contrariwise. Therefore, it is critical to have a balanced, objective and understanding of the economic pros and cons of tourism in local communities. The authors believe that the benefits outweigh the economic detractors to develop the tourism industry sustainably. Tourism is an important sector and is regarded as a tool for economic development for less developed economies. Figure 1 proffers a conceptual model for tourism development. This model will form the basis of the dialectics on pro-poor tourism development. The researchers will also discuss the interrelating factors and variables of impact-oriented research on domestic tourism development.

The tourism sector contributes to the composition of the country's economy in various ways, such as the sale of products and services, business profits, income to residents, job creation, and tax revenues. The proponents of tourism cite numerous economic benefits as a factor for local economic development that stimulates local employment opportunities, foreign currencies earnings, and balance of payments. Local tourism marketing is of great importance to its growth (Švajdová, 2018). These factors are addressed below in more detail. 


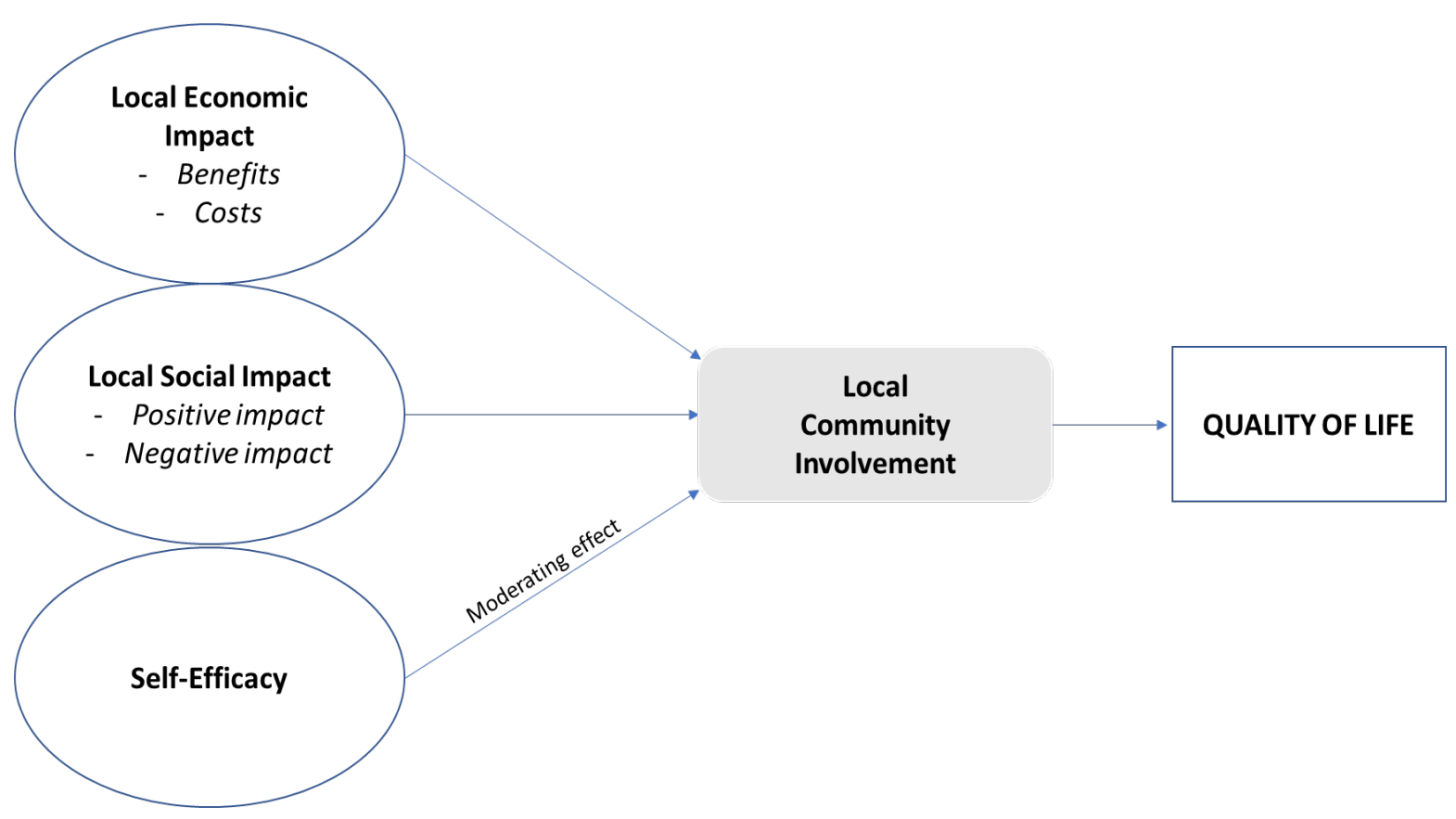

Figure 1: Conceptual model for tourism development

\section{Employment Opportunities}

Tourism creates jobs through increased spending driven by demand that occurs within the primary tourism sectors, for example, the need for accommodation, movement, leisure, food, and drinks that should be satisfied through the development of lodges, transport services, restaurants, retailing, amusement and recreations, and local craft sales. The employment opportunities in these primary tourism sectors depend heavily on international and domestic visitors into the local host regions or communities. Figure 2 is the graph that shows the total number of visits to Namibia from the year 2013 - 2018. It is the total number of tourist arrivals per annum, which hypothetically means an increase in job creation in the primary tourism sectors.

The literature (Luis and Martín, 2004; Fayissa et al., 2008; Du A Franke et al., 2015; Bojanic and Lo, 2016; De Vita and Kyaw, 2016; Chiu and Yeh, 2017) inform that there is evidence of tourism's income-generating capacity within the local communities. Additionally, many researchers (Luis and Martín, 2004) have used the tourist receipts data to estimate the impact of tourism on a country's economy. This desk research found that evidence of jobs created in the tourism sector has significantly impacted local communities. The literature (Fayissa et al., 2008) posited that human capital (employment) is directly developed through tourism, contributing significantly to economic growth. It is argued that tourism receipts stimulate the employment opportunity factor of an economy, but it has a significant effect on per capita income. The researchers found a significant impact between tourism receipts and Africa's income per capita growth rate. Therefore, it may be argued (Fayissa et al., 2008.) that tourism receipts may be considered a vital representation of direct spending into communities. The activities of tourists, pass-through or hosting, in a country tend to stimulate the human capital and the creation of employment of the locals. The locals who serve the tourists as they spend on goods and services from businesses located in the destination areas directly benefit through wages and salaries. 


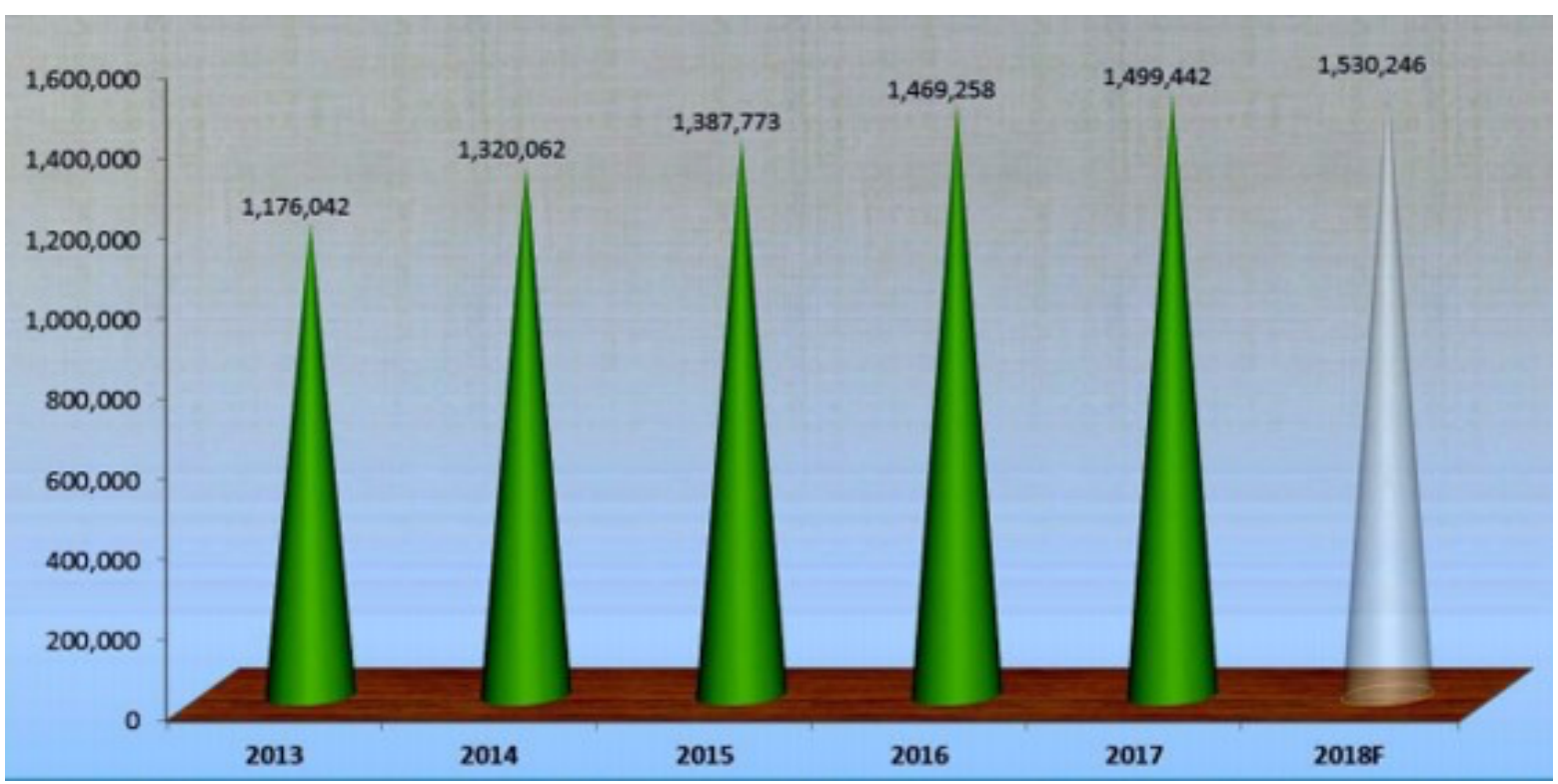

Figure 2: Total number of tourist arrivals per annum

Source: Namibia tourist statistical report 2017

\section{Foreign-Exchange Earnings and Balance of Payment}

It is sound economics and beneficial for any country to earn more money from the rest of the world than it pays outside its borders. The basic economic theory implies that the country's sales should outweigh the purchases when transacting with international tourists to have a positive balance of payments for the tourism sector. Hence, to grow the foreign exchange earnings (exports) over the imports (money departing the country), a country or a region should attract tourists through continuous development of its recreational offerings, resorts and promote domestic tourism. The tourism sector is dynamic and requires constant investment and growth to attract international and domestic tourists. Table 1 summarizes the total domestic trips and expenditures recorded in Namibia for the year 2015. It shows the total expenditure of $\mathrm{N} \$ 6.3$ billion on domestic tourism. It illustrates the enormous potential domestic tourism has on the balance of payment and its impact on the local economy. The survey results further showed that the overall profile for both day and overnight trips is between 25 - 45-year-old. This statistic accounts for between $40 \%$ to $45 \%$ of all travelers within the borders of Namibia.

In terms of gender comparison, the survey found parity representation between males and females, accounting for $51 \%$ of day trips and $48 \%$ of overnight trips. At the same time, the prime destinations for recreational-related domestic trips are Swakopmund (coastal town) and Etosha national park. The illustration here is that Namibia has a vast potential to grow its tourism sector. This can best be achieved by attracting more international tourists to Namibia while at the same time proactively developing its domestic tourism sector.

Table 1: Total trips and expenditure of domestic tourism in Namibia, 2015

\begin{tabular}{|l|r|r|r|}
\hline & \multicolumn{1}{|c|}{ Day Trips } & Overnight Trips & \multicolumn{1}{|c|}{ Total } \\
\hline Trips (m) & 2.05 & 3.74 & 5.79 \\
\hline Spend/Person/Day or Night (N\$) & 993 & 220 & - \\
\hline Total Spend (N\$ billion) & 2.04 & 4.26 & 6.30 \\
\hline
\end{tabular}

Source: Namibia Domestic Tourism Expenditure Survey 2015

Several prior studies, for example that of (Archer, 1995; Durbarry, 2002; Mill and Morrison, 2002) that have been conducted on the impact of tourism on a local economy have shown earning of foreign currencies as one of the significant antecedents that stimulate local economies in developing countries as one of the key economic benefits. As a developing 
country and one of the leading tourist destinations in Southern Africa, Namibia can capitalize on the economic benefits of foreign money earnings derived from the arrival of more visitors. This implies that the effects of tourism on the local economy are positive because of the earnings of a considerable number of foreign currencies infused into the local economy, which also forms part of government revenues.

The infusion of foreign money into the local communities carries either direct or indirect benefits. The direct effect is the actual expenditure on goods and services obtained or experienced by tourists. On the other hand, the indirect effect can be explained as extensions to the use of the money once it circulates through the local economy. The money spent by tourists in the Namibian economy is significant. The income from tourism has a multiplier effect in financing many productive projects, such as reinvestment into Namibian marketing attractions in overseas markets; provision of a source of income for many local transport shuttles; and salaries and wages of the local employees, who render services in the companies which host tourists. Figure 3 below illustrates the direct and indirect effects of foreign money infused into the local economy.

\section{Economic Costs}

Tourism is promoted and celebrated in many countries despite the economic development status. However, as much as we celebrate and promote tourism worldwide, there are an increasing plethora of complaints from community stakeholders. Although Tourism is considered to be one of the largest and fastest-growing sectors in the world which creates employment, improves infrastructure and economic growth, to mention a few, the sector, however, also makes several negative socio-economic and cultural factors that have an impact on the local communities (Tourism and Change, 2015).

According to Boz (2017), tourism is a social, economic, cultural, and environmental phenomenon seen as significant for income generation, employment source, and foreign currency earner (Boz, 2017). It also plays a considerable role in economic development in underdeveloped and developing countries (Peace et al., 2016). However, as far as it has many positive impacts on these economies, there are also many unforeseeable and hidden negative social impacts on the host communities. The most common adverse effects are the disappearance of local traditions and habits, cultural deteriorations, intercultural conflicts, losing cultural identity, and loss of authenticity (Boz, 2017).

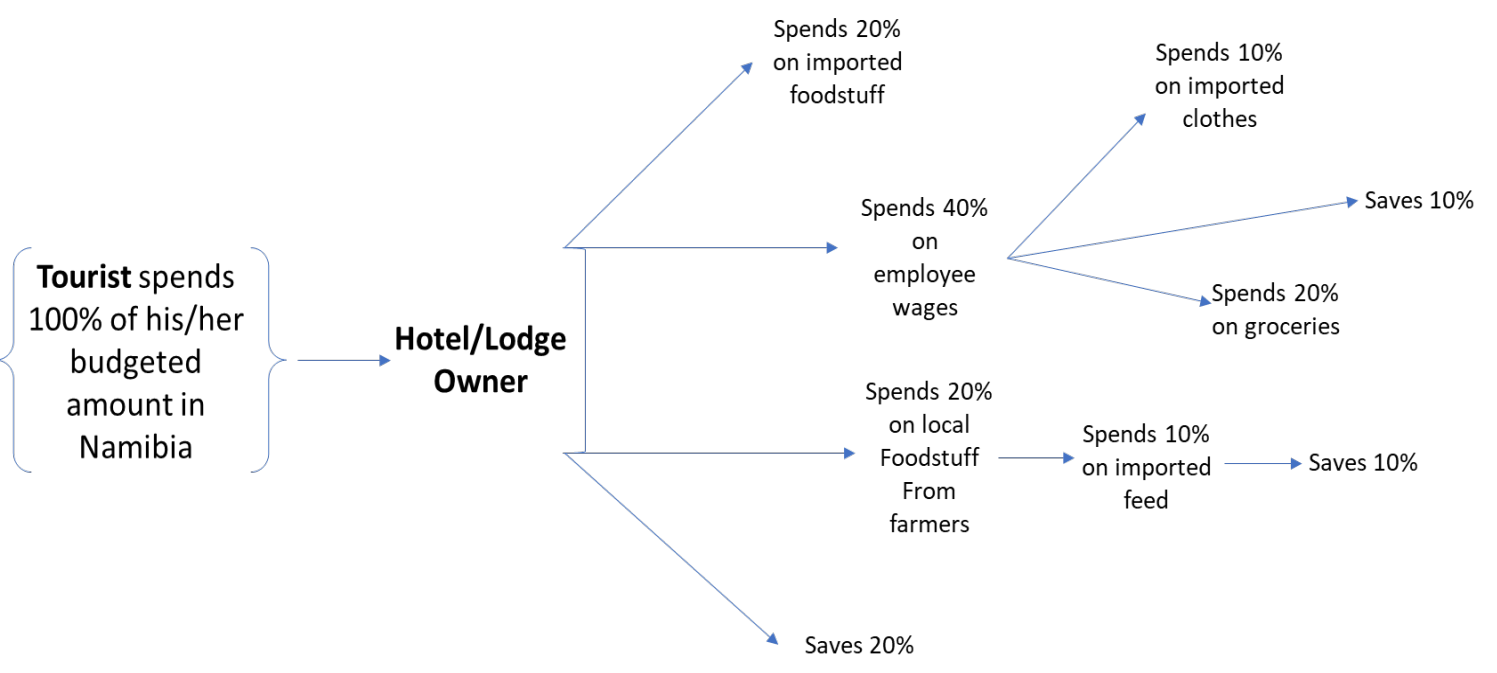

Figure 3: Direct and Indirect Effect of Foreign Earned Money

Tourism can negatively impact the local community, but it can be minimized and measured against the positive effects of tourism. The positive impacts are much more than the negative impacts and are usually not considered critical compared to tourism's benefits (Ahmed, 2018). The researchers posit that any further development of the tourism sector here in Namibia may result in the indigenous communities losing their cultural identity, primarily through catering to the perceived needs of international tourists. The alternative being argued here is a policy shift to sustainable tourism, which is a more thoughtful approach. The accepted theoretic is that sustainable tourism helps ensure a suitable balance between economic, environmental, and socio-cultural aspects of development within the tourism sector. Furthermore, it also 
ensures that the impact on the environment and cultures are minimized, thus not having any malaise on the future generation. Hence this section reports on the number of concerns to the local communities, which is also referred to in this article as the local economy in Namibia.

\section{Over-Dependence on Tourism.}

It is an appalling concern for many developing countries to over depend on tourism to pursue economic growth and development. According to (Harcombe, 1999), no country or town can keep its economy healthy by relying on one industry, the tourism industry. Tourism growth is unpredictable, making it risky for any country to base its economy on the tourism sector solely. Tourism, in general, is influenced by many internal and external factors, which are often not stable. Internal factors that generally influence tourism, amongst others, are changes in the price of goods and services and changes in trends and fashion. While the external factors can be associated with political instabilities, availability and cost in energy, and fluctuations of currencies, both in the tourists' home and destination countries. The development of a balanced economy can serve as a solution to curbing tourism over-dependence. A balanced economy entails the result of many sectors such as mining, agriculture, et cetera to contribute to Namibia's economy.

\section{Inflation and Property Values}

Namibia is currently experiencing economic concerns in the price of properties and the costs of goods and services due to an increase in the influx of tourists from Angola in recent years. Windhoek, the capital city of Namibia, is ranked as one of the most expensive cities in Africa in which to live and own property (Chiringa, 2019). This demonstrates how tourism development elevates the prices related to real estate and general costs of goods and services, which eventually leads to inflation. In addition, the expenditure on tourism to expand the industry can lead to inflation (Shaari et al., 2017). When tourists arrive in a country, they will spend their money on accommodation, transportation to move from one attraction to another, recreational activities, food and drinks, et cetera. This will be incremental on the already existing demand for those goods and services that may cause prices to escalate. Therefore, the aggregate demand tends to have an inflationary effect on the economy.

\section{Opportunity Costs}

When the government of Namibia or local government decides to invest its scarce resources in encouraging the development of tourism, it means they have decided to forego the opportunity to support those scarce resources in other vital sectors, such as agriculture and manufacturing industries, perhaps that is more crucial to the country's economic growth and development. Hence, the government and the general public should be aware of the opportunity costs incurred from tourism investments. Given the opportunity cost of the facilities and infrastructure development that had to be deferred in other economic sectors of the country.

Tourism development requires a substantial capital investment, especially in its initial stages, which requires a great deal of public and private expenditure on the infrastructure and facilities that promote tourism. The developing countries, in most cases, cannot afford to finance the costs of these infrastructure and facility developments (Harcombe, 1999). When less-developed countries find themselves in this predicament, they turn to foreign developed countries and corporations for assistance, resulting in the accumulation of national debt. Also, the profits gained from the cooperation of constructing infrastructure, facilities, and the attraction of tourists are sent back to the home country. This is the economic paradox of tourism development for many African and other developing countries. The infusion of foreign money towards local tourism development and the locals' well-being remains unimproved (Prasad, Guohua, and Asa, 2009).

\section{Self-Efficacy}

Belk (1992) defines self-efficacy as an individual's belief is in their ability to execute work and exhibit rational behavior in a physical and social environment. Bandura (1995) adds that self-efficacy exists when people believe that their acts and management within that environment facilitate benefits. Hence, self-efficacy sums up local community involvement, leading to quality of life (Firouzmakan, 2015). The authors accept that countervailing debate may arise on the concept of quality of life due to self-efficacy in the tourism sector. Hence wise, this paper takes cognizance that various factors construct quality of life, but some of the elements are a result of tourism contribution into the local communities. The existence of efficacy in the communities towards tourism development has a way of 'rubbing off these feelings among the tourists. A study conducted by (Lunenburg, 2011) posits that self-efficacy is the people's self-assessment within their communities on their ability to work to achieve desired performances. Rampullo and Licciardello (2015) add that self- 
efficacy has a positive impact on an individual's performance to achieve stipulated goals so that an individual can direct the resources towards the goals. The self-motivation and fulfillment driven from self-efficacy fundamentally impact human well-being that ultimately improves their quality of life. This paper underlines that the linkage between selfefficacy and quality of life requires human emotional well-being towards tourism and the environment. Local community involvement is a prerequisite to the activities and work that improves the quality of the environment where tourism thrives. It is necessary to involve local communities in tourism development as it incites people's comfort in being satisfied with the acts and rationally support. The engagement of communities in controlling their surrounding is significant. So far, as satisfying the human need to manage the social situations within the parameters of the environment they exist (Belk, 1992), which relates to their quality of life.

The moderating effect of self-efficacy in this paper is seen as the endogenous effect of the belief among local communities to develop an attractive tourism sector based upon their knowledge, skillfulness, and competency, which stimulates them to devote their energy to creating their environment streamlined to attract more international and domestic tourists. For example, skillfulness can serve as a unique source for attracting tourists and a source of income to those involved in avocations such as artistic carvings. Furthermore, the knowledge aspect lies in identifying tourists 'preferences and needs when planning their traveling. This identification process is crucial in engaging tourists in their planning process to consider your local environment as their preferred destination (Garcia-Marques and Mackie, 2001). As a result, we assume that self-efficacy positively influences the involvement of local communities in tourism development which has positive implications on their quality of life regarding social and economic bearings.

\section{Social Impact}

One safeguard of sustainable tourism requires that communities be involved in the planning and implementation process of tourism. In addition, local communities should be more supportive and instead have a positive attitude towards tourism development, thus resulting in a more profitable tourism sector. One of the main elements of sustainable tourism development is community development and involvement (Khandare, 2018). When engaging in sustainable tourism, the social-cultural and environmental negative impacts usually experienced in this sector are generally not permanent and not irreversible.

For many years the tourism industry has become such an essential subject for the governments and regional agencies to improve socio-economic issues because it creates direct income and employment opportunities to the host country and the marginalized communities in those countries. In the Namibian context, tourism is used as a mechanism for achieving many societal and economic goals (Kavita and Saarinen, 2016; Kavita and Jarkko, 2016). The impacts of tourism on local communities are generally universal; one can consider various positive socio-cultural impacts such as employment opportunities, income generation, infrastructure development, and improvement in social services such as telecommunications and banking services. However, at the same time, there are also several negative socio-cultural impacts on local communities, such as the adoption of western cultures, such as dressing styles and racism, and cannibalization of local cultures and languages (Scholtz, 2014). Although there are several negative social impacts, tourism should be considered an element of community enrichment since various cultures come together. Visitors and host communities can learn from each other, not only in terms of different cultural behaviors and values but also in sharing business ideas and seizing opportunities in developing the local communities and the Namibian entrepreneurs (Zaei, 2013).

\section{Recommendation and Conclusion}

The study of the impact of tourism development on the local communities in Namibia represents an important research topic in the emerging literature on tourism and poverty alleviation. This paper makes several contributions by discussing the empirical evidence regarding tourism's impacts on local communities. The researchers found that there is a belief that tourism development has not been inclusive in Namibia (Kavita and Saarinen, 2016). Therefore, it is felt that social inclusion programs should be a priority in tourism development plans. Furthermore, one expects that projects supported by governments and international agencies and the corporate social responsibility strategy of tourism enterprises in local communities should be a priority of public policy development. While there is a general tendency for studies to be narrowly focused on the economic impacts of tourism, this paper also considers the socio-cultural distortion in the scale of development in the local communities. 
This paper also emphasizes the relevance of education and training in an attempt to increase the contribution of tourism to local communities. Therefore, there should be education and training programs to build human capital assets amongst these communities, including primary education and training in social skills and tourism industry operations (e.g., accommodation, food, beverage, transport, guided tours), management, and entrepreneurship. Therefore, it is of utmost importance that the service providers in the tourism industry operate not to disadvantage the tourists, be they international or local tourists, since the sector is dependable on these tourists. The service providers should ensure that their employees are well trained in providing a world-class quality service to the tourists. These employees have the work ethos, which schooled a good understanding of the importance of tourism, and the positive impact on the economic development resulting from there. Such initiatives could maximize economic benefits for the poor in terms of employment, revenue generation, and limited dependence on foreign companies. The literature posited that education and training could also promote local communities' empowerment, involvement in decision-making, and ownership of physical assets and enterprises.

The paper took the view that the local governments of the affected communities could be more proactive and design tax rebates and reductions, and financial incentives (e.g., access to favorable loans, micro-credits, crowdsourcing for funding) for the residents of the local communities (Medina-Muñoz, Medina-Muñoz, and Gutiérrez-Pérez, 2016), and spearheading partnership in a triple-helix public policy initiative for local tourism (Sunitiyoso, et al., 2012). The challenge is made in this paper is that government's revenues from tourism should be invested in local communities to provide propoor essential services (e.g., education, health, transport, social assistance).

Furthermore, the government should ensure that development policies are implemented and supported. (Saarinen, 2010) opines that there is instead a minimum level of awareness of tourism and its impact and how the communities need to interact with tourists. The policies mainly in place are usually guided solely by the benefits received from tourism. The level of knowledge on the impacts of tourism, especially the positive outcome of tourism development, can be improved through awareness campaigns and training. Implementing such a strategy could help local communities become agents in tourism development instead of being negative and not active participants and beneficiaries in national tourism developments.

The government should also ensure that the local people are well informed about the importance of tourism and its impact on economic development. The locals should understand the importance of tourism so that they do appreciate the tourists visiting Namibia. This will, in the process, create not only awareness but also reduce the ill events that happen to the tourists visiting Namibia. Public education presentations can be done in the communities, at schools, tertiary institutions, trade shows, and at the annual tourism Expo. The media, through radio interviews, on the different radio channels, can also be used where government representatives inform the local community about the importance and positive impact of tourism. Given this growth impetus, all stakeholders are willing to work together, and the right policies and governance structures are implemented. One expects that the tourists' experience of Namibia will make the country the preferred tourist destination. This will, therefore, result in constant growth and development of the Namibian infrastructure and economy.

Another contribution of this study is the discussion of the efficacy of the tourism context (i.e., tourism products and markets) as a significant factor influencing the impacts of tourism on local communities. The paper took the view of proffering the moderating effect of tourism on the local communities. The germane idea is that promoting sustainable and inclusive tourism products (e.g., NTB) would be advisable., ecotourism, cultural tourism, volunteer tourism) and markets (e.g., green tourists, tourists interested in knowing the local culture, members of NGOs), and responsible tourism enterprises and NTB initiatives. These tourism products, markets, and organizations are also expected to increase local procurement by tourism enterprises and tourists, strengthening the linkages between tourism and the remaining local sectors. Moreover, consciousness-raising programs could be designed and implemented to promote sustainable, responsible, and inclusive tourism amongst tourism enterprises and tourists at the destination (Medina-Muñoz et al., 2016).

This paper presents an integrated research framework that may guide future empirical research in this field. Besides considering the tourism context as a factor explaining the impacts of tourism on local communities, the framework (Figure 1) embraces a measurement model that could be applied to measure the self-efficacy and the moderating effect of the circular flow from tourism initiatives in local communities. Moreover, the list of tourism's possible impacts could 14 
be considered an exploratory scale to measure the economic and socio-cultural effects. The framework also suggests associations between tourism initiatives at different levels of analysis, the positive and negative social impacts, and a wide variety of economic, socio-cultural impacts of tourism. An adequate understanding of the associations is subject to further empirical research.

In conclusion, the study observes that outbound travel by Namibians is a response to a lack of choice locally and recommends the diversification of the product and experience offering in Namibia. This strategy would be a rebranding of the domestic tourism market. In addition, this study suggests that education, awareness campaigns, and concessionary rates for residents during the off-season period are also recommended to sensitize the Namibians about product offerings within the country and address the affordability issue (Ministry of Environment and Tourism, 2008). Therefore, it is of utmost importance that stakeholders such as the local communities, the government, and service providers in the sector collaborate in the policy formulation, implementation, and monitoring of a sustainable tourism strategy for Namibia.

\section{References}

- Ahmed, M. (2018). Guesthouses in the Maldives: Towards community-based tourism. International Journal of Innovation and Economic Development, 4(1), 44-50.

- Asa, A. R., \& Prasad, N. S. (2014). Analysis on the factors that determine sustainable growth of small firms in Namibia. International Journal of Management Science and Business Administration, 1(1), 5-11.

- Archer, B. (1995). Importance of tourism for the economy of Bermuda. Annals of Tourism Research. CrossRef

- Bandura, A. (1995). Self-efficacy in changing societies. Cambridge University Press.

- Belk, R. W. (1992). Attachment to Possessions. In-Place Attachment (pp. 37-62). Springer US. CrossRef

- Bojanic, D. C., \& Lo, M. (2016). A comparison of the moderating effect of tourism reliance on the economic development for islands and other countries. Tourism Management, 53, 207-214.

- Boz, M. (2017). Impact of Tourism Industry on Host Communities: Antalya and Canakkale Cases. Researcher Social Science Studies, 1(8), 153-170. CrossRef

- Chiringa, K. (2019). Windhoek is rated the sixth most expensive city in Africa. Retrieved September 20, 2019, from https://www.thevillager.com.na/articles/14440/windhoek-rated-sixth-most-expensive-city-in-africa/

- Chiu, Y. Bin, \& Yeh, L. T. (2017). The Threshold Effects of the Tourism-Led Growth Hypothesis: Evidence from a Cross-sectional Model. Journal of Travel Research, 56(5), 625-637. De Vita, G., \& Kyaw, K. S. (n.d.). Tourism development and economic growth. CrossRef

- Du A Franke, D. W., Lew, A. A., Ng, P. T., \& Franke, W. A. (2015). Tourism and Economic Growth. Journal of Travel Research.

- Durbarry, R. (2002). Long-run structural tourism demand modelling: An application to France.

- Fayissa, B., Nsiah, C., \& Tadasse, B. (2008). Impact of tourism on economic growth and development in Africa. Tourism Economics, 14(4), 807-818. CrossRef

- Fayissa, B., Nsiah, C., \& Tadasse, B. (n.d.). The Impact of Tourism on Economic Growth and Development in Africa.

- Firouzmakan, S. (2015). Promotion quality of life by increasing place attachment in public places. Elsevier. Retrieved from https://www.sciencedirect.com/science/article/pii/S1877042815048454

- Garcia-Marques, T., \& Mackie, D. M. (2001). The feeling of familiarity as a regulator of persuasive processing.

- Harcombe, D. (1999). The economic impacts of tourism. Retrieved from http://repository.au.edu/bitstream/handle/6623004553/13273/abacj-v19-n2-2.pdf?sequence=1

https://www.sciencedirect.com/science/article/pii/S1877042815050478 CrossRef

- Initiatives through Triple Helix Interactions: Systems Modelling for Policy Development. Procedia - Social and Behavioral Sciences, 52, 140-149. CrossRef

- Inventory, F., Of, R., \& Region, C. (1998). Ministry of Environment and Tourism Directorate of Forestry. Forest Research, (December).

- Kavita, E. \&, \& Jarkko. (2016). Tourism and rural community development in Namibia: policy issues review; Tourism and rural community development in Namibia: policy issues review. CrossRef 
- Kavita, E., \& Saarinen, J. (2016). Tourism and rural community development in Namibia: Policy issues review. Fennia, 194(1), 79-88. CrossRef

- Khandare, V. (2018). Social and Cultural Impact of Tourism Development in Thailand 1., 8(2), 877-887.

- Luis, J., \& Martín, N. (2004). Tourism and Economic Growth in Latin American Countries: A Panel Data Approach.

- Lunenburg, F. C. (2011). Self-Efficacy in the Workplace: Implications for Motivation and Performance. International Journal of Management (Vol. 14).

- M Scholtz. (2014). A critical assessment of the social impacts of tourism in selected South African Communities. Potchefstroom.

- Medina-Muñoz, D. R., Medina-Muñoz, R. D., \& Gutiérrez-Pérez, F. J. (2016). The impacts of tourism on poverty alleviation: an integrated research framework. Journal of Sustainable Tourism, 24(2), 270-298.

- $\quad$ Mill, R. C., \& Morrison, A. M. (2002). The tourism system. Kendall Hunt.

- Ministry of Environment and Tourism. (2008). National sustainable tourism growth and investment promotion strategy 2016-2026. New Directions for Youth Development, 2008(120), 7-12. CrossRef

- $\quad$ NPC (2017). Namibia's 5. Namibia's 5th National Development Plan (NDP 5), 7.

- Peace, O.E., Izuchukwu, O. \& Shehu, A.A. (2016). Exchange rate fluctuation and tourism sector output in Nigeria. International Journal of Management Science and Business Administration, 3(1), 48-55.

- Prasad, N. S., Guohua, Y., \& Asa, A. R. (2009). Fiji' s Transformation from Sugar to Tourism Industry, $1221-$ 1224.

- $\quad$ Rampullo, A., Licciardello, O., \& Castiglione, C. (2015). Intrapersonal factors effects on professional orientation and environmental representations. Procedia-Social and Behavioral Sciences, 205, 422-428.

- Saarinen, J. (2010). Local tourism awareness: Community views in Katutura and King nehale Conservancy, Namibia. Development Southern Africa, 27(5), 713-724. CrossRef

- Shaari, M. S., Salha, T., Ahmad, T., \& Razali, R. (2017). Tourism Led-Inflation: A case of Malaysia. Social Cognition, 19(1), 9-34. CrossRef

- Sunitiyoso, Y., Wicaksono, A., Utomo, D. S., Putro, U. S., \& Mangkusubroto, K. (2012). Developing Strategic

- Švajdová, L. (2018). Modern marketing communication in tourism. Journal of International Business Research and Marketing, 4(2), 20-23.

- Tourism, L., \& Chang, G. (2015). Socio-Economic Impacts on Local Community through Tourism Development with Special Reference to Heritance Kandalama (Vol. 2). Dambulla-Kandalama. Retrieved from http://geog.nau.edu/igust/srilanka2014/

- Tribe, J., \& Liburd, J. J. (2016). The tourism knowledge system. Annals of Tourism Research. CrossRef

- Walpole, M. (2000). Local economic impacts of dragon tourism in Indonesia. Elsevier. Retrieved from https://www.sciencedirect.com/science/article/pii/S0160738399000882

- Zaei, M. (2013). The impacts of tourism industry on host community. European Journal of Tourism Hospitality and Research. 